\title{
Vinca alkaloids Produced by Endophytic Fungi Isolated from Vinca plants
}

\author{
L. I. Abdulmyanova, D. M. Ruzieva, R. S. Sattarova* and T. G. Gulyamova \\ Department of Biochemistry and Biotechnology of Physiologically Active Compounds, \\ Institute of Microbiology of the Academy of Sciences RU, Uzbekistan
}

*Corresponding author

\section{A B S T R A C T}

\section{Keywords \\ Vinca plants, endophytic fungi, cytotoxicity, bio- active natural products, vinca alkaloids \\ Article Info \\ Accepted: 20 May 2018 Available Online: 10 June 2018}

Seventeen strains of endophytic fungi have been isolated from three species of Vinca plants - V. minor, V. erecta and $V$. rosea collected from different areas of Uzbekistan. These endophytic fungi represented different genera and were screened for vinca alkaloids production. Out of the seventeen endophytic fungal cultures screened, extracts of 5 strains contain compounds of alkaloid nature (vinblastine and vincristine).

\section{Introduction}

Endophytic fungi are recognized as one of the richest sources of natural products displaying a broad spectrum of biological activities. The reported natural products from endophytes includes antibiotics, antipathogens, immunosupressants, anticancer compounds, antioxidant agents and other biologically active substances (Aly et al., 2008; Guo et al., 2008; Gutierrez et al., 2012; Hazalin et al., 2009; Padhi et al., 2013; Pimentel et al., 2011; Wang et al., 2014; Zhang et al., 2006). The phytochemistry of endophytic microbes continues to increase in significance and there 400 natural products are known to date, of which most have novel structures and/or useful biological activities, from 128 plant- associated microorganisms. Over the last ten years more than 100 compounds with significant cytotoxic activity including camptothecin, diosgenin, hypericin, paclitaxel, podophyllotoxin, vincristin, which have pharmaceutical importance have been obtained from endophytic fungi of various plants (Joseph and Priya, 2011). Some endophytes produce certain phytochemicals, originally characteristic of the host, due to a genetic recombination of the endophyte with the host that occurred in evolutionary time. Several endophytes producing plant metabolites isolated from Vinca (family Apoceanacea) plants. For example, vinca alkaloid vincamine, known under the trade name oksibral, originally received from Vinca minor (Yin and Sun, 2011). This compound 
has been detected in endophytes isolated from leaves of V.minor growing in Iran (Farahanikiaa et al., 2011). Vincristine, also known as leurocristine, is a vinca alkaloid originally isolated from endophyte Fusarium oxysporum inhabiting the leaves of periwinkle Catharanthus roseus (syn. Vinca rosea) (Kumar et al., 2013).

From $V$. minor, $V$. erecta and $V$. rosea (syn. Catharhantus roseus) grown in Uzbekistan we isolated 17 strains of fungal endophytes and 5 of which showed pronounced cytotoxic activity against Hep-2, HBL-100 and HeLa cell lines (Abdulmyanova et al., 2015; Abdulmyanova et al., 2016). Phytochemical studies of Vinca plants are quite well developed, and their medical use, in particular, $V$. rosea and $V$. minor due to antitumor, hypoglycemic, hypotensive, cerebral effects of their metabolites (Kharwar et al., 2005; Singh et al., 2001). Since microbial fermentation has several advantages over the plant raw materials use for obtaining of medicinal preparations and substances, study of cytotoxic compounds from endophytic fungi of Vinca plants can create an alternative way for their production. In this context, the aim of the present work was the study of the nature of secondary metabolites produced by endophytic fungi associated with Vinca plants.

\section{Materials and Methods}

\section{Study area and material sampling}

$V$. minor, $V$. erecta and $V$. rosea plants were collected in March 2016 and 2017 on the territory of Tashkent city neighborhoods (Uzbekistan). Plant samples were identified and stored in a herbarium.

\section{Isolation of endophytic fungi}

Endophytic fungi were isolated by the method as described previously by Hazalin et al.,
(Hazalin et al., 2009). Roots, stems and leaves were respectively washed in tap water, sterilized in $70 \%$ ethanol for 1 min followed by $0.1 \% \mathrm{HgCl}_{2}$ for $7 \mathrm{~min}$, rinsed three times in de-ionized water, cut into segments approximately $5 \mathrm{~mm}$ in diameter and placed in $90 \mathrm{~mm}$ Petri dishes containing Czapek-Dox agarized medium with $50 \mathrm{mg} / \mathrm{ml}$ chlortetracycline and $250 \mathrm{mg} / \mathrm{ml}$ streptomycin sulfate to inhibit bacterial growth.

The plates were incubated for 7-14 days at 28 ${ }^{\circ} \mathrm{C}$. Different mycelia growing out of the segments were sub-cultured and individually maintained on antibiotics-free Czapek-Doxagar medium. Colony morphology and growth and spore formation of the isolates were then studied on Potato-Dextrose-agar medium.

\section{Endophytic fungi identification}

Isolated strains were identified by classical methods on the basis of morphology using pertinent monographs (Litvinov, 1967). Isolated strains were deposited at the Institute of Microbiology of the Uzbekistan Academy of Sciences where they were maintained at +4 ${ }^{\circ} \mathrm{C}$.

\section{Fermentation}

To accumulate biomass for further extraction and determination of biological activity, endophytes were grown by submerged fermentation in $500 \mathrm{ml}$ flasks containing 100 $\mathrm{ml}$ of Chapek-Dox liquid medium for 5 days at $28{ }^{\circ} \mathrm{C}$.

\section{Results and Discussion}

A total of 17 morphologically distinct fungal isolates were isolated and identified from three species of Vinca plants - V. minor, V. erecta and $V$. rosea obtained from different areas of Uzbekistan. It was found that extracts of 5 strains contain compounds of alkaloid nature. 
Fig.2 HPLC analysis of total extracts of endophytic fungi isolated from Vinca plants
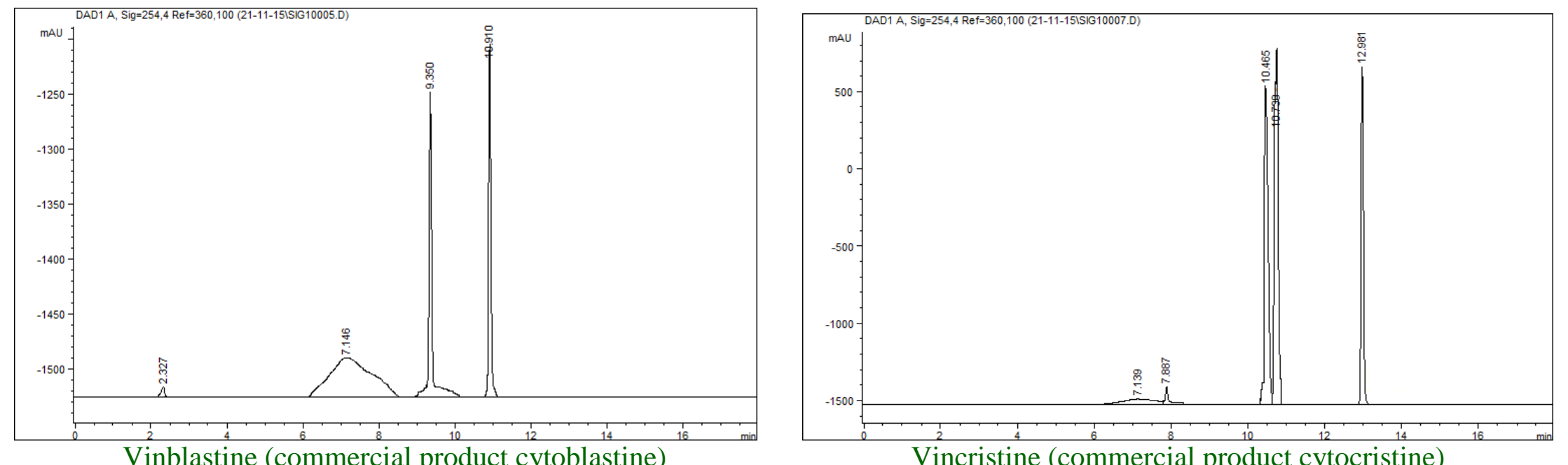

a) cytocristine (vincristine) and cytoblastine (vinblastine)

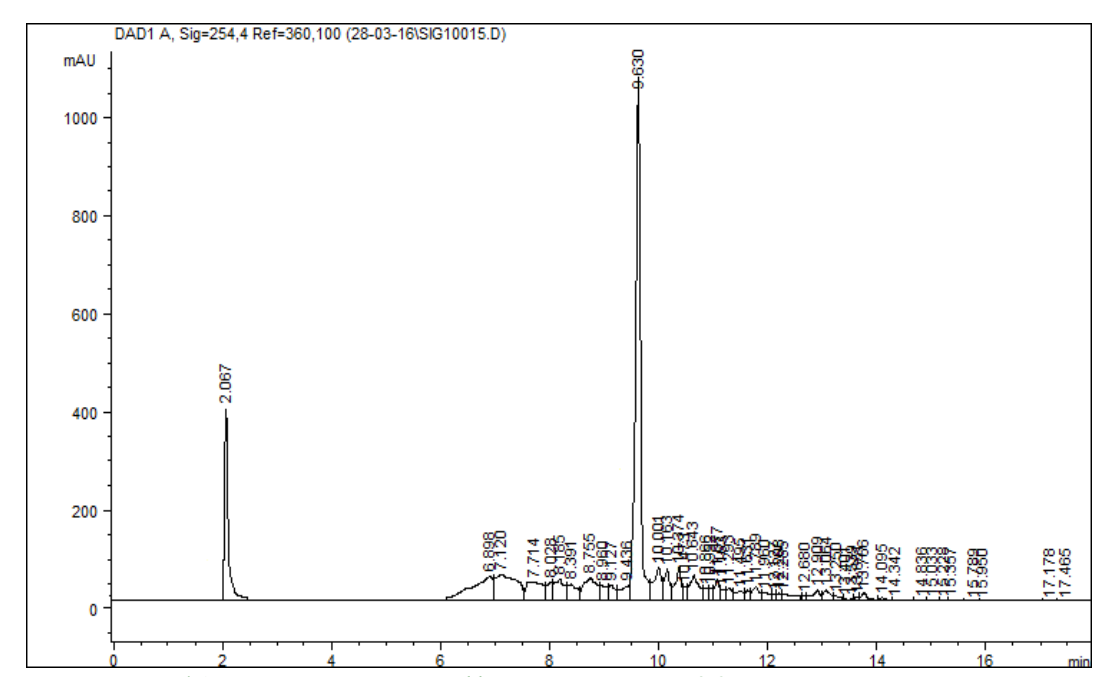

b) extract Penicillium sp. - VE89L

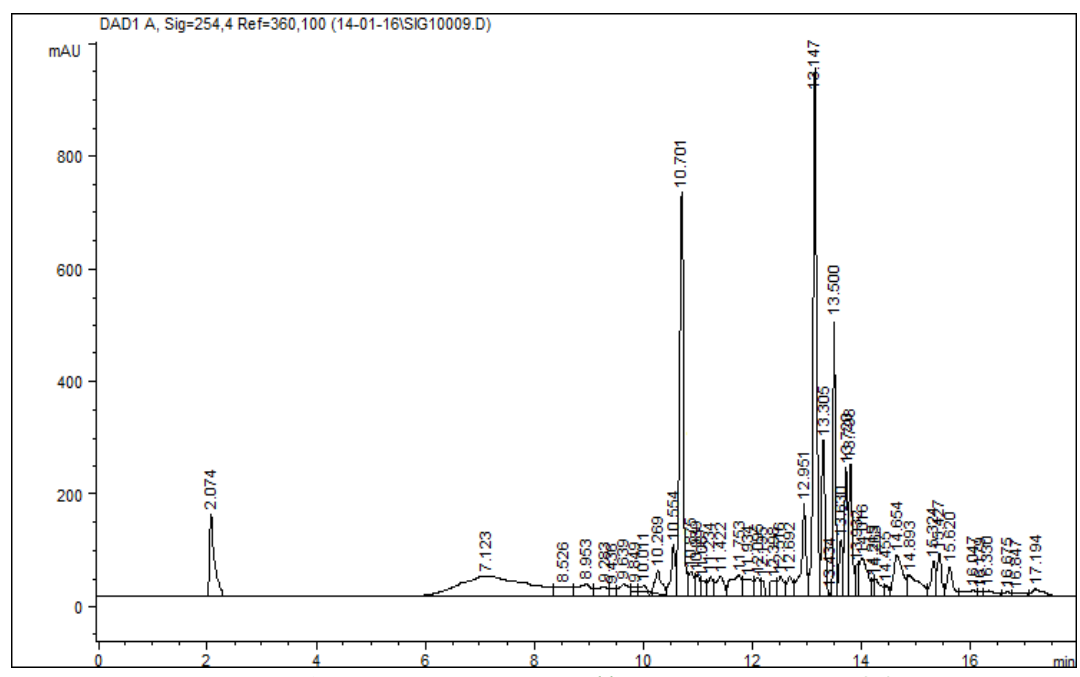

c) extract Aspergillusterreus - VE90R 


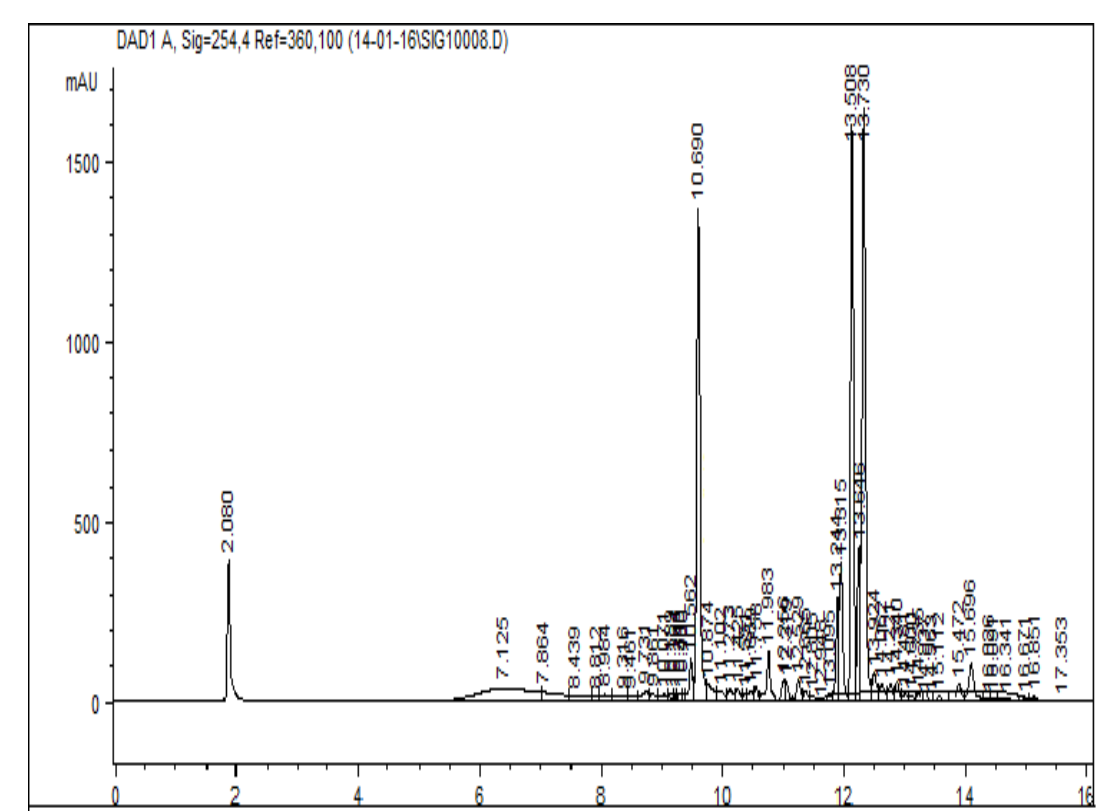

d) extract Cladosporium sp. - VE92L

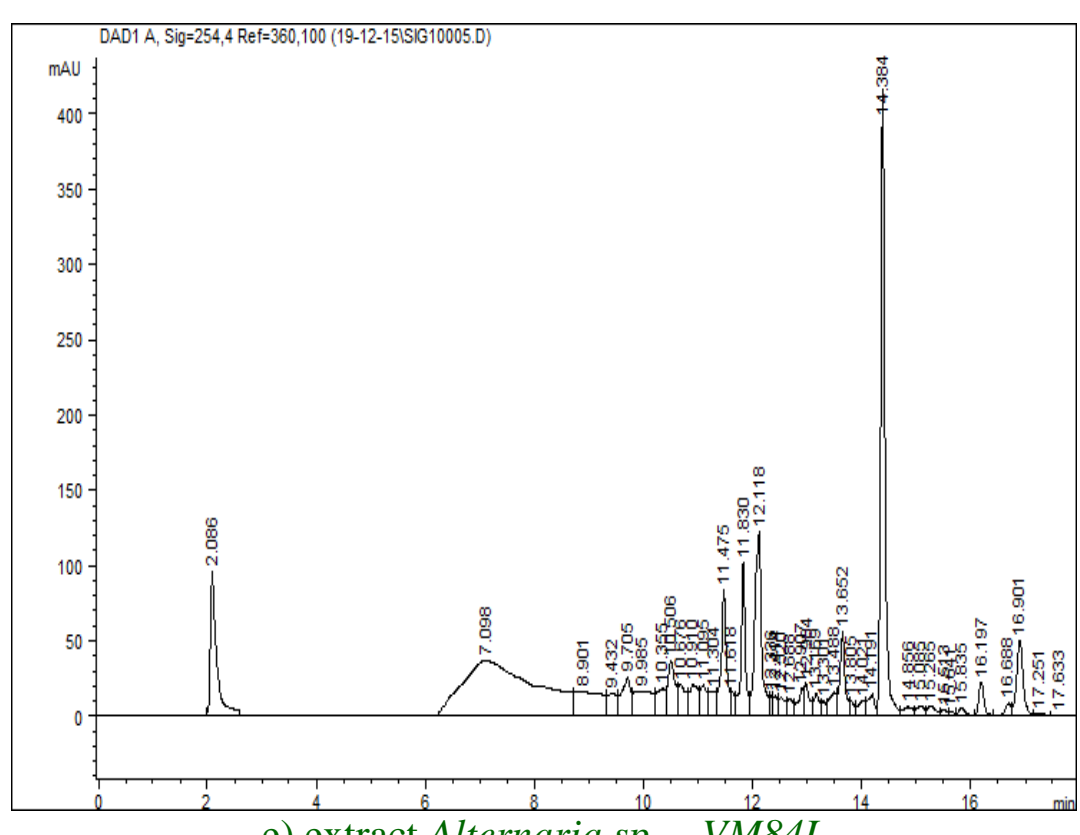

e) extract Alternaria sp. - VM84L

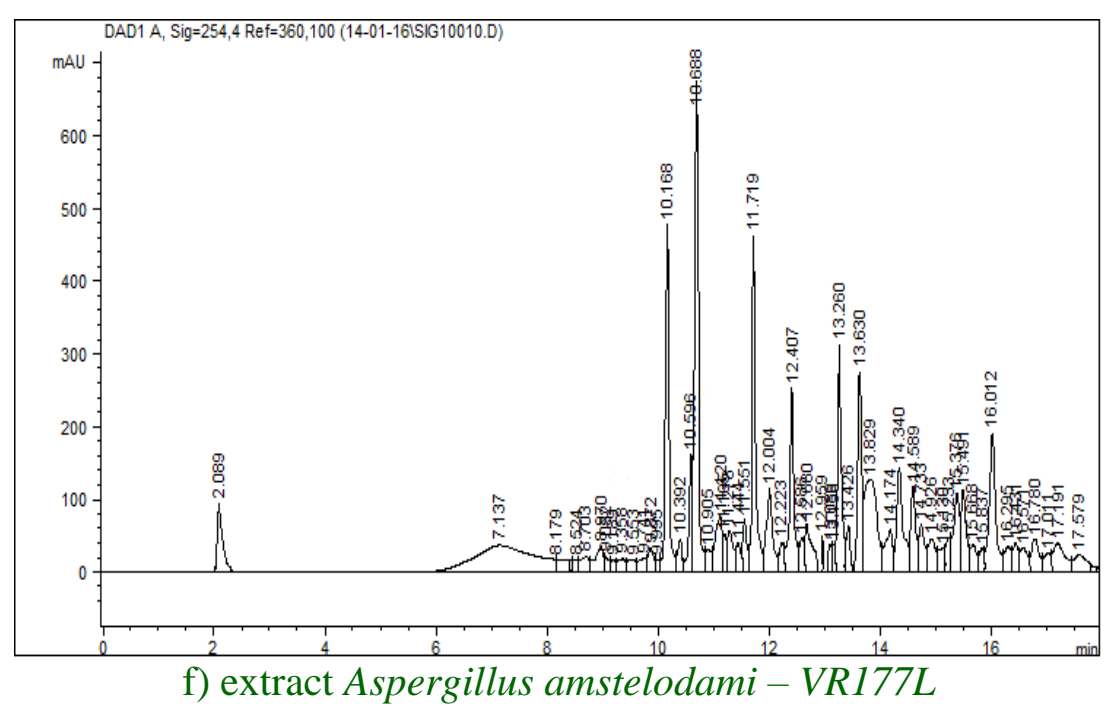


Fig.1 TLC analysis of extracts of endophytic fungi isolated from Vinca plants

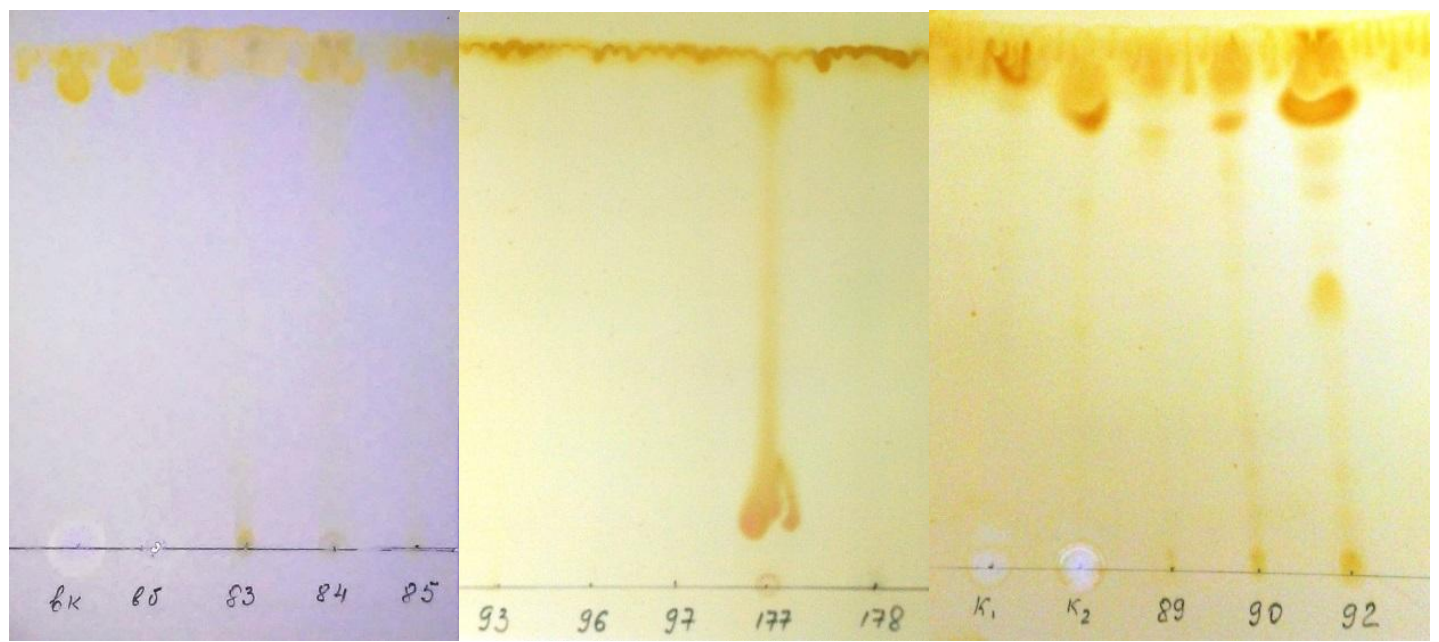

Thin-layer chromatography of these extracts determined the presence of compounds corresponding to vinblastin and vincristine in extracts of two strains Penicillium sp.-VE89L and $A$. terreus-VE90R, and the presence of compound corresponding to vinblastin in extracts of three strains identified as Alternaria sp.-VM84L, Cladosporium sp.VE92L and A. amstelodami-VR177L (Fig. 1).

However, comparative analysis of chromatograms of the total extracts of endophytic fungi and commercial products cytocristine (vincristine) and cytoblastine (vinblastine) by HPLC showed the presence of peaks which coincides with the time of release in extracts of all studied strains: Penicillium sp.-VE89L, A. terreus-VE90R, Cladosporium sp.-VE92L, Alternaria sp.VM84L and A. amstelodami-VR177L.

In quantitative terms, the highest content of vincristine is defined in the extract of endophyte Penicillium sp.-VE89L isolated from leaves of $V$. erecta (Fig.2).

In previous studies we have shown that extracts of endophytic fungi Alternaria sp.VM84L, Penicillium sp.-VE89L, A. terreusVE90R, Cladosporium sp.-VE92L,
A.amstelodami-VR177L as well as Penicillium sp.-VM86S, Penicillium sp.VE93R, Alternaria tenuis-VE98L and other have cytotoxic activities. Pronounced growth inhibition was showed by incubation of extracts with cultured cells of HBL-100.

Presented in this report, the results indicate that the cytotoxic effect of the extracts may be due to the presence of vinblastine and vincristine.

The production of these compounds by endophytes of Vinca plants, which grows on the territory of Uzbekistan, can serve as a basis for the development of study of these endophytic fungi as source of new anticancer drugs.

\section{References}

Abdulmyanova L.I., F.K. Fayzieva, Ruzieva D.M., Gulyamova T.G. 2016. Biological activity of secondary metabolites of fungal endophytes from Vinca. Journal of theoretical and clinical medicine. Tashkent, 1:39-44.

Abdulmyanova L.I., Teomashko N.N., Terent'eva E.O., Ruzieva D.M., Sattarova R.S., Azimova Sh.S., 
Gulyamova T.G. 2015. Cytotoxic activity of fungal endophytes from Vinca. International Journal of Current Microbiology and Applied Science, 4 (7): 321-329.

Aly A.H., Indriani I.D., Edrada-Ebel R.A., Wray V., Mueller W.E.G., Trotzke F., Zirrgiebel U., Schaechtele C., Kubbutat M.H.G., Lin W.; Proksch P., Ebel R. 2008. Cytotoxic metabolites from the fungal endophyte Alternaria $s p$. and their subsequent detection in its host plant Polygonum senegalense. J. Nat. Prod., 71: 972-980.

Farahanikiaa B., Akbarzadehb T., Jahangirzadeha A., Yassaa N., Ardekania M.R.S., Mirnezamia M., Hadjiakhoondia A., Khanavia M. 2011. Phytochemical investigation of Vinca minor cultivated in Iran. Iranian Journal of Pharmaceutical Research, 10 (4):777-785.

Guo B., Wang Y., Sun X., Tang K. 2008. Bioactive natural products from endophytes: a review. Appl. Biochem. Microbiol., 44 (2): 136-142.

Gutierrez R.M.P., Gonzalez A.M.N., and Ramirez A.M. 2012. Compounds derived from endophytes: a review of phytochemistry and pharmacology. Current Medicinal Chemistry, 19: 29923030.

Hazalin N.A., Ramasamy K., Lim S.M., Wahab I.A., Cole A.Lj., Majeed A.A. 2009. Cytotoxic and antibacterial activities of endophytic fungi isolated from plants at the National Park, Pahang, Malaysia. BMC Complementary and alternative medicine, 9: 46.

Joseph B., Priya R.M. 2001. Bioactive compounds from endophytes and their potential in pharmaceutical effect: a review. American journal of
Biochemistry and Molecular Biology, 1(3): 291-309.

Kharwar R.N., Verma V.C., Strobel G. 2005. The endophytic fungal complex of Catharanthus roseus (L.) G. Don. Current science, 95 (2): 228-233.

Kumar A., Patil D., Rajamohanan P.R., Ahmad A. 2013. Isolation, Purification and characterization of vinblastine and vincristine from endophytic fungus Fusarium oxysporum isolated from Catharanthus roseus. Plos one, 8 (9): 110.

Padhi L., Mohanda Y.K., Panda S.K. 2013. Endophytic fungi with great promises: a review. J. Adv. Pharm. Edu. \& Res., 3 (3): 152-170.

Pimentel M.R., Molina G., Dionırsio A.P., Marorstica M.R., Pastore G.M. 2011. The use of endophytes to obtain bioactive compounds and their application in biotransformation process. Biotechnology Research International, 1-13.

Singh S.N., Vats P., Shyam R., Kumria M.M., Ranghanathan S., Sridharan K. 2001. Effect of an antidiabetic extract of Catharanthus roseus on enzymic activities in streptozotocin induced diabetic rats. J. Ethnopharmacol., 76: 269-277.

Wang Y.1, Yang M.H.2, Wang X.B.1, Li T.X.1, Kong L.Y. 2014. Bioactive metabolites from the endophytic fungus Alternaria alternata. Fitoterapia, 99: 153-8.

Yin H., Sun Y.H. 2011. Vincamine producing endophytic fungus isolated from Vinca minor. Phytomedicine, 18 (8-9): 802-5.

Zhang H.W., Song Y.C., Tan R.X. 2006. Biology and chemistry of endophytes. Nat. Prod. Rep., 23: 753-771. 


\section{How to cite this article:}

Abdulmyanova L. I., D. M. Ruzieva, R. S. Sattarova and Gulyamova T. G. 2018. Vinca alkaloids Produced by Endophytic Fungi Isolated from Vinca plants. Int.J.Curr.Microbiol.App.Sci. 7(06): 2244-2250. doi: https://doi.org/10.20546/ijcmas.2018.706.267 